\title{
Unidades didácticas y desarrollo de habilidades comunicativas en el aula ${ }^{1}$
}

\author{
Mario Fernando Reinoso Gómez
}

Recibido: 14-07-2017

Aceptado: 03-11-2017

\section{RESUMEN}

Este artículo se basa en el trabajo de investigación que está orientado hacia el fortalecimiento de las habilidades comunicativas en los estudiantes del grado noveno de una institución educativa pública del municipio de Bucaramanga. Para ello se planteó la preparación y ejecución de unidades didácticas que incorporaron actividades de aula que estimularon a los estudiantes en sus procesos comunicativos. Para llevar a cabo este proyecto se tuvo en cuenta la investigación cualitativa desde el enfoque de la investigación-acción ya que el elemento fundamental de la misma es la sociedad, representada en el grupo de estudiantes que son objeto de este estudio. De esta manera, este trabajo se denominó: Unidades didácticas como estrategia para el fortalecimiento de las habilidades comunicativas en los estudiantes del grado noveno de una institución pública del municipio de Bucaramanga.

En principio, se pudo establecer que existe una marcada dificultad en los procesos de comprensión de lectura por parte de este grupo de estudiantes. Dicha falencia, se hace evidente en los resultados de las pruebas SABER que, a la par con la prueba diagnóstica de lenguaje, expuso otras dificultades que van más allá de lo que registran las pruebas estandarizadas. Problemas en las habilidades para redactar, sostener argumentos de forma oral y dificultades a la hora de escuchar a sus pares y docentes, se suman a la deficiente comprensión lectora. A raíz de lo anterior, surgió la necesidad de implementar una serie de acciones

1. Este artículo se sustenta en el trabajo de investigación titulado: Unidades didácticas como estrategia para el fortalecimiento de las habilidades comunicativas en los estudiantes del grado noveno de una institución pública del municipio de Bucaramanga.

2. Universidad Autónoma de Bucaramanga. Facultad de Ciencias sociales Humanidades y Artes - Maestría en Educación. Licenciado en español y literatura, aspirante al título de Magister en Educación de la facultad de educación de la UNAB. Docente de la institución educativa La Medalla Milagrosa de Bucaramanga.

Correo electrónico: mreinoso@unab.edu.co - marioferego@gmail.com 
orientadas a la mejora de las habilidades comunicativas durante (12) meses de implementación y análisis. Este proceso estuvo enmarcado en la formulación de (3) unidades didácticas que integraron el desarrollo de las cuatro habilidades comunicativas (leer, escribir, hablar y escuchar), contando con el enfoque y la orientación de la teoría de desarrollo del lenguaje de Noam Chomsky, puesto que este autor se ha destacado en el estudio y evolución de las destrezas comunicativas a lo largo del desarrollo de procesos formativos en los seres humanos. La reflexión final condujo a establecer que el desarrollo de las unidades didácticas aquí propuestas derivó en una notoria mejoría en los procesos comunicativos de los estudiantes, y a su vez, brindó una nueva perspectiva de la aproximación a los temas desde un modelo dinámico que contó con la participación activa de los implicados y desde ya se proyecta para su ejecución en otros grados y materias.

Palabras clave: unidades didácticas, habilidades comunicativas, procesos de lectura y escritura, desarrollo de competencias.

\title{
Didactic units and development of communicative skills in the classroom
}

\begin{abstract}
This article is based on the research work is oriented toward the strengthening of communicative skills in the ninth grade of an educational institution in the municipality of Bucaramanga. To this objective, it is proposed the preparation and execution of didactic units that incorporate classroom activities that stimulate students in their communicative processes. To carry out this project was taken into account the qualitative research from the research-action approach since the fundamental element of it is the society, represented in the group of students that are the object of this study. In this way, this work was denominated: Didactic units as strategy for the strengthening of the communicative abilities in the ninth grade students of a public institution of the municipality of Bucaramanga.
\end{abstract}


In principle, it was possible to establish that there is a marked difficulty in the processes of reading comprehension by this group of students. This failure is evident in the results of the SABER tests, which, along with the diagnostic test of language, exposed other difficulties that go beyond what the standardized tests record. Problems in writing skills, oral arguments and difficulties in listening to mates and teachers, add to the poor reading comprehension. As a result of the above, there was a need to implement a series of actions aimed at improving communicative skills for twelve (12) months of implementation and analysis. This process was framed in the formulation of three (3) didactic units that integrated the development of the four communicative skills (reading, writing, speaking and listening), with the focus and orientation of Noam Chomsky's theory of language development, Since this author has excelled in the study and evolution of the communicative skills throughout the development of formative processes in the human beings. The final reflection led to establish that the development of the didactic units proposed here resulted in a noticeable improvement in the communicative processes of the students, and in turn, provided a new perspective of the approach to the subjects from a dynamic model that counted on the Active participation of those involved and is already planned for implementation in other grades and subjects.

Keywords: didactic units, communicative skills, reading and writing processes, competence development.

\section{Introducción}

El uso del lenguaje en el contexto educativo reviste vital importancia en el éxito o fracaso de los procesos de aprendizaje. Para algunos científicos, desde la concepción se van desarrollando las habilidades esenciales que componen el complejo entramado de estructuras lingüísticas que componen el lenguaje oral y escrito. De cierta manera es como si el ser humano viniera predispuesto a comunicar.

En el marco de esta premisa, se asume que el desarrollo de las capacidades del lenguaje optimizaría las cualidades comunicativas de los sujetos que hacen parte de los procesos de enseñanza-aprendizaje. Particularmente esta es la razón de ser de este trabajo de investigación 
ya que se concibe desde la necesidad de reforzar las habilidades propias del lenguaje a partir de la formulación de unidades didácticas que contemplen el fortalecimiento de la capacidad de leer, escribir, escuchar y hablar correctamente de acuerdo al contexto y las necesidades dadas por las circunstancias comunicativas.

Es así como se entendió la necesidad de generar unidades didácticas concebidas en el propósito de hacer que estos estudiantes implementaran sus habilidades comunicativas en el aula con el ánimo de fortalecerlas a la par con la eventual mejoría en la pruebas estandarizadas para que se diera la posibilidad de hacer que estas habilidades se constituyeran en una mejora en la calidad de vida al hacer que su forma de expresarse sea verbal o escrita, se ajuste a las circunstancias requeridas al igual que la capacidad de lectura y de escucha. Adicionalmente, las unidades didácticas expuestas en el presente trabajo recogen elementos contemplados en los estándares básicos de competencias del lenguaje, el plan de área de lengua castellana para el grado noveno y los derechos básicos de aprendizaje para la creación y aplicación de unidades didácticas que integren el desarrollo de las cuatro habilidades comunicativas.

\section{Metodología y fundamentación conceptual}

Para la elaboración y ejecución de este proyecto se tuvo en cuenta el enfoque de la metodología de investigación denominada InvestigaciónAcción, en tanto se busca transformar una realidad a través de la comprensión y el análisis del entorno socio-cultural que enmarcan las carencias en los niveles de interpretación y producción de textos orales y escritos.

En este contexto educativo, esta metodología permite contemplar las dificultades encontradas por los docentes en cuanto a las deficiencias en el proceso de lectura y escritura de textos como una situación transformable a partir de las prácticas educativas y de la mano con el respectivo análisis de los factores que inciden en dicha problemática para encontrar alternativas procedimentales que acerquen los estudiantes hacia la meta de mejorar sus competencias comunicativas.

Con este precedente, se dio inicio a la elaboración de una serie de estrategias orientadas al fortalecimiento sustancial de las habilidades 
comunicativas enmarcadas en el desarrollo de unidades didácticas que integren estas habilidades alrededor de la puesta en escena del tratamiento habitual de algunos temas comprendidos en el plan de área de lengua castellana para el grado noveno. En consecuencia, se planeó esta propuesta de intervención en el aula a través de varias etapas que se configuran en función de potenciar el uso efectivo del lenguaje en los estudiantes. Estas etapas se desarrollaron paulatinamente de acuerdo a un cronograma estructurado desde las siguientes fases: preparación, reflexión inicial, planificación, acción-observación y reflexión parcial. Todo ello, articulado de forma continua con el fin de exaltar el carácter cíclico de la investigación acción.

En el desarrollo de este trabajo de investigación se tomó como referentes algunos proyectos de investigación como: "Lengua y Literatura: disciplina escolar. Hacia una metodología circunstanciada de su enseñanza" (Cuesta, 2011); "Plan de estrategias didácticas para la optimización de competencias de comprensión lectora en los estudiantes de la media general" (Díaz R. , 2014); "La lectura dialógica como medio para la mejora de la comprensión lectora" (Gutiérrez Fresnada, 2016); "Desarrollo de la comprensión en lectura inferencial del grado noveno de un Colegio Público de Bogotá" (Contreras, 2016); "Docentes y literatura: La experiencia de lectura como punto de reflexión" (Aponte, 2014); "Estrategias metodológicas para la comprensión lectora en tres instituciones educativas de básica secundaria, de Bogotá" (Arrieta, Gomajoa, \& Soto, 2015); "Propuesta didáctica para la lectura de un texto literario con estudiantes de noveno grado de una institución pública de la ciudad de Bucaramanga" (Paternina, 2016); "La lectura comprensiva y la composición de textos como estrategia para el desarrollo de la competencia comunicativa" (Correa Parra, 2012); "Actividades lúdicorecreativas como estrategia para mejorar la comprensión lectora en los estudiantes del grado décimo uno de la institución educativa Agustina Ferro de la ciudad de Ocaña" (Lobo, 2016), estos documentos cuentan un nivel de cercanía en términos de tiempo y manejo de estrategias para incentivar los procesos cognitivos relacionados con el uso del lenguaje. La propuesta esencial que se planteó está orientada hacia la formulación de unidades didácticas que fortalecieron las habilidades comunicativas de los estudiantes. En principio se tuvo en cuenta el concepto de Amparo Escamilla quien define la unidad didáctica de la siguiente manera:

"La unidad didáctica es una forma de planificar el proceso de enseñanza-aprendizaje alrededor de un elemento de contenido 
que se convierte en eje integrador del proceso, aportándole consistencia y significatividad. Esta forma de organizar conocimientos y experiencias debe considerar la diversidad de elementos que contextualizan el proceso (nivel de desarrollo del alumno, medio sociocultural y familiar, Proyecto Curricular, recursos disponibles) para regular la práctica de los contenidos, seleccionar los objetivos básicos que pretende conseguir, las pautas metodológicas con las que trabajará, las experiencias de enseñanza-aprendizaje necesarios para perfeccionar dicho proceso" (Escamilla, 1993, pág. 39).

En este sentido, las unidades didácticas se pueden asumir como una serie de actividades de aula enmarcadas en experiencias de aprendizaje que son mediadas y orientadas por el profesor aunque él no es un determinante absoluto del proceso de aprendizaje.

Por otra parte, el desarrollo de las habilidades comunicativas es un tema que ha sido objeto de investigación parra un gran número de autores. Para el caso particular de esta investigación, se toma como referente lo aportado por el filósofo y lingüista estadounidense Noam Chomsky en cuanto a su teoría lingüística. Vale la pena hacer la aclaración de que las teorías del lenguaje no han logrado un nivel de perfección que contemple verdades absolutas en la formulación de sus premisas como lo afirma (Chomsky, 1999) "estamos muy lejos de poder presentar un sistema de universales lingüísticos formales y sustantivos que sea lo suficientemente rico y detallado para dar razón de los hechos del aprendizaje del lenguaje" (p. 44). No obstante, se debe realizar el ejercicio de intentar establecer supuestos generales de la naturaleza del lenguaje con el fin de realizar el acercamiento a los procesos que lo potencializan en función de su uso adecuado en determinada circunstancia. En este sentido, las teorías lingüísticas contribuyen al estudio de los procesos mentales y la capacidad intelectual humana en función del aprendizaje del lenguaje.

En principio, Chomsky aborda el desarrollo del lenguaje en su etapa inicial desde el enfoque del innatismo entendido como la concepción de que algunas nociones fundamentales del entendimiento, entre ellas el lenguaje, vienen preconcebidas desde antes de nacer. Esta premisa la fundamenta con el soporte de varios teóricos que coinciden en la idea de que el ser humano nace facultado para asumir conceptos esenciales de la lingüística. Ahora bien, el autor menciona que el desarrollo de las facultades también está mediado por la experiencia (Chomsky, 
1999)"Parece evidente que la adquisición del lenguaje se basa en que el niño descubre lo que, desde un punto de vista formal, es una teoría profunda y abstracta - una gramática generativa de su lengua -, muchos de cuyos conceptos y principios están relacionados con la experiencia" (p. 56).

En su modelo de aprendizaje del lenguaje, Chomsky elabora un constructo teórico centrado en la explicación de los principios y procesos detrás de la producción de sentido en las construcciones sintácticas en las lenguas. Sus estudios acerca del desarrollo del lenguaje a partir de los esquemas de pensamiento van desde los cimientos en edades tempranas, hasta la etapa en que el individuo se vale de los conceptos adquiridos para transformar las unidades subyacentes del lenguaje en lo que cualquier hablante entiende. Para efectos de la presente investigación, se toma el principio de que el ser humano cuenta con un organismo de adquisición del lenguaje que se adecua e integra nuevos conceptos organizacionales en la medida que se ve expuesto a situaciones de comunicación.

El lenguaje es una propiedad universal que viene integrada en el individuo que admite la participación del contexto en su adquisición y manejo, en consecuencia, la exposición del aprendiz a situaciones comunicativas en un contexto que exige determinadas habilidades deberá derivar en la potenciación de las facultades propias del lenguaje.

De otro lado, el concepto de habilidad, más allá de entenderse como la capacidad para ejecutar acciones con propósito determinado, se comprende como la manera de articular estrategias que optimicen las competencias de un sujeto en aras de un propósito, dicho de otra forma, se trata de saber hacer para lograr un fin. En este sentido la noción de habilidad abarca un contenido más amplio que vincula conocimiento, experiencias, voluntad y capacidad, en torno a un proceso de aprendizaje continuo que modela y orienta al sujeto desde su entorno sociocultural. Adicionalmente, en el desarrollo de las distintas actividades propuestas en el seno de esta investigación, se dio relevancia el concepto de desarrollo del pensamiento crítico de los estudiantes como consecuencia de la interacción entre ellos y con la perspectiva desde los distintos componentes literarios abordados en las unidades didácticas. La importancia de trabajar el pensamiento crítico en el aula es referida por (Hernández, Maldonado, \& Ospina, 2015): "De aquí que cada sujeto debiera tener la oportunidad de entender y desarrollar habilidades críticas, y por esto es fundamental comenzar por comprender en qué 
consiste el pensamiento crítico". De esta manera se entiende que el aula de clase es el lugar ideal para llevar a cabo procesos que impliquen el desarrollo de esta habilidad.

\section{Descripción del proceso}

En el propósito de llevar a cabo las propuestas de la presente investigación se implementaron las siguientes acciones:

1. Prueba diagnóstico: en un primer plano, y de manera consecuente con la etapa de preparación, se acudió al uso de una prueba diagnóstico para establecer las bases conceptuales que sustentan los deficientes resultados en las pruebas estandarizadas. Dicha prueba está orientada a evaluar las cuatro (4) habilidades comunicativas mediante el uso de un cuestionario de comprensión lectora, una propuesta de elaboración de un texto, un cuestionario de valoración de la capacidad de escucha y una breve exposición argumentada sobre una temática de interés juvenil.

2. Prueba valorativa de final: una vez llevado a cabo el desarrollo de las distintas unidades didácticas, se implementó la misma prueba diagnóstico inicial, (haciendo la aclaración que los estudiantes no conocían las respuestas), con el fin de llevar a cabo un acercamiento a las eventuales mejoras que se dieron durante el proceso en términos de mejora de las habilidades comunicativas.

Tabla 1.Competencias comunicativas.

\begin{tabular}{|l|c|c|c|}
\hline \multicolumn{1}{|c|}{$\begin{array}{c}\text { Competencias } \\
\text { comunicativas }\end{array}$} & $\begin{array}{c}\text { Porcentaje de } \\
\text { aprobación } \\
\text { inicial }\end{array}$ & $\begin{array}{c}\text { Porcentaje de } \\
\text { aprobación } \\
\text { final }\end{array}$ & $\begin{array}{c}\text { Porcentaje } \\
\text { incrementado }\end{array}$ \\
\hline $\begin{array}{l}\text { Prueba de } \\
\text { comprensión lectora }\end{array}$ & $28.125 \%$ & $46.6 \%$ & $18.5 \%$ \\
\hline $\begin{array}{l}\text { Prueba de } \\
\text { producción escrita }\end{array}$ & $37.5 \%$ & $53.3 \%$ & $15.8 \%$ \\
\hline $\begin{array}{l}\text { Prueba de } \\
\text { producción oral }\end{array}$ & $46.875 \%$ & $56.6 \%$ & $9.7 \%$ \\
\hline $\begin{array}{l}\text { Test de escucha } \\
\text { activa }\end{array}$ & $53.125 \%$ & $57.7 \%$ & $4.6 \%$ \\
\hline Total & $41.4 \%$ & $53.5 \%$ & $12.15 \%$ \\
\hline
\end{tabular}


3. Unidades didácticas: como respuesta a las necesidades evidenciadas en el planteamiento del problema se planificaron tres (3) unidades didácticas que se estructuraron en sesiones tendientes al tratamiento explícito de una temática del plan de área de lengua castellana, e implícito en cuanto al desarrollo de las distintas habilidades comunicativas. Con este propósito, se tiene en cuenta el aporte conceptual de Noam Chomsky en cuanto el desarrollo y la evolución del uso del lenguaje en determinado contexto, también denominado Actuación lingüística, ya que fue fundamental en la elaboración de la secuencia de actividades propuestas en las unidades didácticas. Como este autor sugiere, en las actividades de aprendizaje se dio espacio en forma individual y combinada al desarrollo de las habilidades comunicativas por medio de la exposición del educando a distintas necesidades de expresión. En principio, el desarrollo de las sesiones en el aula estaba concebido para la escucha activa acerca de reflexiones teóricas con participaciones orales espontáneas de las estudiantes, manifestadas a través de preguntas. Adicionalmente, se brindaron espacios para la lectura y creación de textos orales y escritos junto con la preparación de un proyecto de aula grupal en el cual se vieron avocados a trabajar en la consecución de un objetivo común.

\section{Unidad didáctica ideal para el fortalecimiento de las habilidades} comunicativas. Como producto de la reflexión y el análisis del desempeño de las anteriores unidades didácticas se plantea una unidad didáctica modelo para el fortalecimiento de las habilidades comunicativas.

Tabla 2. Unidad didáctica ideal para el fortalecimiento de las habilidades comunicativas.

\begin{tabular}{|l|l|l|}
\hline Área & Unidad didáctica No & Título de la unidad didáctica \\
\hline Fecha de ejecución: & & $\mathrm{N}^{\circ}$ de sesiones: \\
\hline Justificación & $\begin{array}{l}\text { En este apartado se mencionan los motivos por los cuales se realiza la unidad didáctica o de dónde } \\
\text { surge la necesidad de llevarla a cabo. Debe ser clara y concreta, además de ubicar al lector en el } \\
\text { plano de las acciones a elaborar en búsqueda de alcanzar el propósito de aprendizaje. }\end{array}$ \\
\hline Objetivos & $\begin{array}{l}\text { En ellos se suscribe lo que se busca que los estudiantes adquieran como consecuencia de la } \\
\text { implementación de la unidad didáctica. }\end{array}$ \\
\hline \hline Logros a desarrollar & Procedimental \\
\hline Conceptual & $\begin{array}{l}\text { En cuanto a las habilidades que } \\
\text { se desarrollaron en la búsqueda } \\
\text { de un objetivo de aprendizaje y } \\
\text { las herramientas para lograrlo. }\end{array}$ & $\begin{array}{l}\text { Refiere la disposición para el } \\
\text { aprendizaje y la contribución del } \\
\text { estudiante al ambiente de aula. }\end{array}$ \\
\hline $\begin{array}{l}\text { En lo referente a lo conceptual } \\
\text { se espera que logre el avance } \\
\text { en el dominio del tema. }\end{array}$
\end{tabular}




\begin{tabular}{|c|c|c|c|c|c|}
\hline \multicolumn{6}{|l|}{ Metodología } \\
\hline \multicolumn{6}{|c|}{$\begin{array}{l}\text { Es un esbozo de la manera como se llevará acabo las actividades de aula. Si obedecen como tal a } \\
\text { una metodología predeterminada o si se hace bajo un enfoque plurimetodológico. Se espera que la } \\
\text { metodología contribuya al desarrollo de las habilidades del lenguaje. }\end{array}$} \\
\hline \multicolumn{6}{|l|}{ Transversalidad } \\
\hline \multicolumn{6}{|c|}{$\begin{array}{l}\text { Se trata de darle sentido amplio al proceso de aprendizaje al vincularlo con otras disciplinas. Aquí se } \\
\text { menciona cómo se da esta noción integradora. }\end{array}$} \\
\hline \multicolumn{6}{|c|}{ Actividad de inmersión } \\
\hline \multicolumn{6}{|c|}{$\begin{array}{l}\text { En principio se recomienda dar inicio a la temática de la unidad didáctica con una actividad que la } \\
\text { presente de manera dinámica y atractiva. De este primer acercamiento depende en gran medida la } \\
\text { disposición para el aprendizaje de los estudiantes. }\end{array}$} \\
\hline \multicolumn{6}{|c|}{ Planeación de las actividades } \\
\hline \multicolumn{6}{|c|}{$\begin{array}{l}\text { Para la planeación de las actividades de la unidad didáctica, se plantea tomar en cuenta los } \\
\text { momentos del proceso de enseñanza-aprendizaje dentro de las sesiones. Estos momentos adaptan } \\
\text { el fundamento que propone (Ally, 2002) para aprendizaje online y se integran a la planeación a } \\
\text { modo de ruta a seguir, siendo estos: preparación para el aprendizaje, actividades de aprendizaje, } \\
\text { interacción de aprendizaje y transferencia del aprendizaje. Asimismo, se debe disponer de una } \\
\text { serie de actividades en concordancia con estas etapas para hacer del aprendizaje un proceso que } \\
\text { contemple el desarrollo de las habilidades comunicativas. }\end{array}$} \\
\hline \multicolumn{6}{|c|}{ Programación general de la unidad } \\
\hline Momentos & $\begin{array}{l}\text { Desarrollo de } \\
\text { las habilidades } \\
\text { comunicativas }\end{array}$ & $\begin{array}{l}\text { Nombre de la } \\
\text { actividad }\end{array}$ & Proceso & Recursos & Tiempo \\
\hline $\begin{array}{l}\text { Preparación para } \\
\text { el aprendizaje }\end{array}$ & $\begin{array}{l}\text { Fortalecimiento } \\
\text { de la lectura, } \\
\text { escritura, } \\
\text { escucha y habla. }\end{array}$ & $\begin{array}{l}\text { Se recomiendan } \\
\text { actividades de } \\
\text { observación y } \\
\text { análisis. }\end{array}$ & $\begin{array}{l}\text { Descripción } \\
\text { detallada del } \\
\text { proceso. }\end{array}$ & $\begin{array}{l}\text { Elementos } \\
\text { necesarios para } \\
\text { llevar a cabo } \\
\text { el proceso de } \\
\text { enseñanza- } \\
\text { aprendizaje. }\end{array}$ & $\mathrm{N}^{\circ}$ horas \\
\hline $\begin{array}{l}\text { Actividades de } \\
\text { aprendizaje. }\end{array}$ & $\begin{array}{l}\text { Fortalecimiento } \\
\text { de la lectura, } \\
\text { escritura, } \\
\text { escucha y habla. }\end{array}$ & $\begin{array}{l}\text { Se recomiendan } \\
\text { actividades de } \\
\text { fundamentación } \\
\text { e } \\
\text { implementación } \\
\text { de conceptos. }\end{array}$ & $\begin{array}{l}\text { Descripción } \\
\text { detallada del } \\
\text { proceso. }\end{array}$ & $\begin{array}{l}\text { Elementos } \\
\text { necesarios para } \\
\text { llevar a cabo } \\
\text { el proceso de } \\
\text { enseñanza- } \\
\text { aprendizaje. }\end{array}$ & $\mathrm{N}^{\circ}$ horas \\
\hline $\begin{array}{l}\text { Interacción de } \\
\text { aprendizaje }\end{array}$ & $\begin{array}{l}\text { Fortalecimiento } \\
\text { de la lectura, } \\
\text { escritura, } \\
\text { escucha y habla. }\end{array}$ & $\begin{array}{l}\text { Se recomiendan } \\
\text { trabajos grupales } \\
\text { encaminados } \\
\text { al desarrollo de } \\
\text { un proyecto de } \\
\text { aula. }\end{array}$ & $\begin{array}{l}\text { Descripción } \\
\text { detallada del } \\
\text { proceso. }\end{array}$ & $\begin{array}{l}\text { Elementos } \\
\text { necesarios para } \\
\text { llevar a cabo } \\
\text { el proceso de } \\
\text { enseñanza- } \\
\text { aprendizaje. }\end{array}$ & $\mathrm{N}^{\circ}$ horas \\
\hline $\begin{array}{l}\text { Transferencia del } \\
\text { aprendizaje }\end{array}$ & $\begin{array}{l}\text { Fortalecimiento } \\
\text { de la lectura, } \\
\text { escritura, } \\
\text { escucha y habla. }\end{array}$ & $\begin{array}{l}\text { Se recomienda } \\
\text { llevar a cabo la } \\
\text { presentación y } \\
\text { evaluación del } \\
\text { proyecto. }\end{array}$ & $\begin{array}{l}\text { Descripción } \\
\text { detallada del } \\
\text { proceso. }\end{array}$ & $\begin{array}{l}\text { Elementos } \\
\text { necesarios para } \\
\text { llevar a cabo } \\
\text { el proceso de } \\
\text { enseñanza- } \\
\text { aprendizaje. }\end{array}$ & $\mathrm{N}^{\circ}$ horas \\
\hline
\end{tabular}

Fuente. (López Navarro) Modelo para la programación de una unidad didáctica (adaptado por el autor)

\section{Resultados}

\section{En esta etapa, que refiere todo el proceso de análisis de la implementación de la propuesta, se hizo uso de los diarios de campo pertenecientes a las tres unidades. Para su distinción se referirá a $\mathrm{D}$ como todos los diarios de campo de las unidades didácticas.}




\section{Unidades didácticas}

En este apartado, se da cuenta de elementos fundamentales que se relacionan con la construcción de las unidades didácticas entendida como categoría de análisis. En este propósito, se analiza el planteamiento inicial del tema, el manejo del tiempo y la pertinencia de las actividades.

a- Planteamiento inicial del tema: en la ejecución de esta propuesta se dio especial atención a este apartado por lo que en cada una de las unidades se buscó encaminar el inicio de la sesión con una pregunta inductiva que incitaba a la participación dialógica de los estudiantes en torno a la temática propuesta. Ante esto en D: "Para ello acudí a una pregunta que diera pie a la introducción del tema: ¿Cuánto tiempo tardas en llegar al colegio? De esta forma los estudiantes hicieron sus comentarios donde concluimos que el tiempo destinado al desplazamiento hacia el colegio oscila entre 1 a 30 minutos. Con ello se dio espacio para la reflexión en torno a qué tan difícil resulta ir al colegio". En este aspecto es importante señalar que acudir a los conocimientos previos de los estudiantes antes de iniciar con los contenidos teóricos es una herramienta de aprendizaje que mejora sustancialmente el acercamiento al tema. Para (Ausubel D. , 2002), la clave del aprendizaje significativo está en la relación que se pueda establecer entre el nuevo material y las ideas ya existentes en la estructura cognitiva del sujeto. Por lo expuesto, la eficacia de este tipo de aprendizaje radica en su significatividad y no en técnicas memorísticas.

b- Manejo del tiempo: El tiempo es una variable fundamental a la hora de ejecutar una unidad didáctica. En lo concerniente a la propuesta planteada en este trabajo se llevó a cabo cada unidad en un estimado de tres (3) semanas y para tal fin se contó con dos (2) sesiones de dos (2) horas por cada semana. Ahora bien, posterior a cada unidad se implementó una etapa de reflexión y análisis que prolongó relativamente el total de la intervención a un estimado de diez (12) meses. No obstante, en algunas sesiones se tuvo que aplazar la actividad planeada a causa de otras acciones de tipo institucional que obligaron a extender a otras sesiones la ejecución de las actividades propuestas. Por otra parte, se acudió al uso de tiempo extra clase para la elaboración de los proyectos de aula lo cual fue asumido como una esfuerzo adicional por parte de los alumnos para lograr los objetivos propuestos. En suma, el tiempo se tuvo que modificar en función de algunas circunstancias de tipo administrativo y de ejecución de otras actividades de tipo institucional, sin embargo se logró ejecutar lo planeado en la propuesta de intervención en el aula. 
c- Pertinencia de las actividades: las acciones llevadas a cabo en el marco de la ejecución del presente proyecto fueron pertinentes en tanto se concibieron en función de fortalecer las habilidades comunicativas en los estudiantes de grado noveno. Por un lado, se implementaron recursos que viabilizaron avances en cuanto a la expresividad de los estudiantes ya que se vieron avocados a participar de manera voluntaria y espontánea. Por otra parte, el objeto de aprendizaje estuvo encaminado hacia la preparación de un proyecto grupal que reunió a los estudiantes en la búsqueda de logro mancomunado, lo cual los incentivó a aportar en la consecución de ese objetivo contribuyendo de forma importante en la implementación de estrategias comunicativas que fortalecieron aún más su expresividad. Adicionalmente, se debe destacar que el ambiente de enseñanza fue el propicio para desarrollar las actividades y los escasos inconvenientes fueron manejados de forma asertiva por parte del alumnado y del docente.

\section{Recursos}

Para la implementación de las actividades de aula enmarcadas en las unidades didácticas se utilizaron diversos recursos que se refieren a continuación.

a- Imágenes: como ya se mencionó anteriormente, el tratamiento de imágenes reviste vital importancia en el desarrollo de las actividades propuestas en el seno de las unidades didácticas. Es así como en D: "En este momento de la clase se buscó llamar la atención de los mismos hacia el tema haciendo uso de imágenes que evocaran el sentido artístico de las obras literarias que se estaban mencionando, esto con la intención de que ellos visualizaran a manera de collage los referentes conceptuales de las mismas". El uso de imágenes en esta secuencia permitió orientar e ilustrar mejor el proceso de lectura de los estudiantes sobre un tema del cual no había un referente distinto al de la explicación dada por el docente. Es por ello que la imagen en el aula proporciona, entre otros elementos, un soporte importante a las explicaciones verbales pues se focalizó aún más la escucha y el nivel de interés de los estudiantes.

b-Videos: este recurso de soporte audio-visual cada día más presente en los espacios educativos se ha utilizado en la implementación de las unidades didácticas realizadas en este proyecto de investigación. En D se programó así: "De esta manera, se dio paso a la instalación del video-beam para hacer la proyección del documental francés Camino 
a la escuela. Este recurso audiovisual sirvió como ejemplo de la esencia del documental, además de tratar acerca de una temática relevante para ellos puesto que mostró la situación de 5 estudiantes en distintos contextos socioculturales tratando de llegar a la escuela en medio de dificultades muy grandes".

La utilidad del vídeo en el aula radica en que ofrece posibilidades que otros soportes como el audio o el texto escrito no brindan: permite contextualizar cualquier situación de comunicación mostrando la localización espacial y temporal de la actuación comunicativa, apreciar las actitudes y los patrones interactivos de los hablantes y sensibilizar al aprendiz sobre las formas de organizar el discurso, los recursos y los elementos que se utilizan con este fin.

c-Talleres: mediante el uso de este recurso se indujo a los estudiantes al reconocimiento de los conceptos que se trabajaban al inicio de las unidades didácticas y de las cuales ellos debían llevar un registro escrito, además de persuadirlos en el propósito de investigar para complementar sus respuestas y exponerlas en la socialización de los talleres. De esta manera, el uso de este recurso se dio en D así: "A partir de ello se propuso la realización del primer taller que aclara muchos de los conceptos inicialmente explicados por el profesor y por el video. Los alumnos emprendieron la realización del taller y el profesor quedó dispuesto a aclarar dudas al respecto." Para (Gutiérrez, 2017) el uso del taller incide en el desarrollo de las cuatro habilidades básicas hablar, oír, leer y escribir, lo que ayudará al estudiante en su desarrollo integral que como individuo debe alcanzar en su comunicación.

$d$-Textos: en la planificación y ejecución de las actividades de aula, la lectura se hizo presente en diversas formas. A través de lectura de imágenes, lectura de videos, lectura de texto y hasta lectura de jeroglíficos. En D "En ese instante comencé la lectura del primer párrafo mencionando que mi forma de leer se trataba de un ejemplo para el estudiante que siguiera la lectura. De esta manera se fue rotando la palabra hasta terminar el texto". La lectura en voz alta suele asociarse a las clases de educación primaria en las que la voz del docente era la única escuchada durante este ejercicio. Sin embargo, la lectura en grupo trae varias ventajas al ser implementada en la escuela secundaria como se menciona en el documento A viva voz del ministerio de educación chileno (Mineduc, 2013): "...es necesario romper el mito de que es una actividad solo para los niños. 


\section{Estrategias didácticas:}

a-Mapas mentales: el uso de mapas mentales como una forma de esquematizar los conceptos es una herramienta muy útil en los procesos de aprendizaje porque ayuda notablemente en la tarea de aprender y recordar información. A través de este recurso se buscó potenciar las habilidades de los estudiantes en cuanto a la lectura y la escritura de ideas puntuales que después pudieron asociar a conceptos más complejos $y_{1}$ en consecuencia, exponerlos de forma oral con la explicación de los argumentos.

b- Grupo en red social: la red social Facebook sirvió de plataforma para el encuentro virtual con los estudiantes a través de la creación de un grupo en esta red social. La posibilidad de comunicar eventualidades, compartir documentos y publicar trabajos, entre otros, fue muy importante para mantener contacto con los estudiantes del grado noveno. En la etapa inicial de $D$, se utilizó así: "Para ejemplificar mejor el tema del documental, se invitó a los estudiantes a ingresar al grupo de Facebook para ver dos documentales a modo de ejemplo y se les dio la posibilidad de compartir uno o varios documentales para este fin". Por otra parte, en D:"Para la presentación del teatro de títeres se llevó a cabo la filmación de las puestas en escena y se invitó a los estudiantes a compartir sus videos a través del grupo de Facebook". Finalmente en D: "El resultado del trabajo grupal será publicado en el grupo de Face y en la siguiente sesión se hará la exposición de los posters". (Alamo Bernal, Meza De la Hoz, Fernández Santos, \& Abúndez Najera, 2015) Refieren el uso de esta red social así: "Por lo tanto, el uso del Facebook es una de las redes sociales de mayor uso, y es donde la pedagogía aporta bases de conocimiento por medio de la retroalimentación, así mismo, el alumno construye su propio aprendizaje y participa en grupos o foros virtuales de manera respetuosa, pero se debe concientizar y educar su uso". El uso de esta red social para fines educativos ha sido ampliamente referenciado en numerosos estudios que destacan las cualidades de hacer uso de la red social en el ambiente educativo. En un sentido global, esta acción se orientó hacia la intención de incorporar las TIC en los procesos de enseñanza y aprendizaje con el propósito de atender una de las principales necesidades en el actual contexto educativo. (Recalde España, Serna Agudelo, \& Stella Polo, 2015) mencionan la importancia de trabajar este elemento como un soporte a la cualificación del trabajo de los docentes: "la importancia de la integración de las TIC en los procesos de formación de la infancia como una de las principales 
necesidades en el contexto de la educación infantil, teniendo en cuenta los estándares de competencias [...]De igual manera, sensibilizar a los docentes y padres de familia respecto a la importancia del tema de este proyecto como factor esencial en la formación integral de niños y niñas.

c- Método de preguntas: una de las estrategias más frecuentemente usadas en el presente trabajo fue la de realizar una puesta en común del tema trabajado a través de la formulación de preguntas. Con esta modalidad, los estudiantes se vieron llamados a la participación y fueron ganando confianza a la hora de hablar frente a sus compañeros. Por último, se debe mencionar que esta estrategia contribuyó enormemente al fortalecimiento del habla en los estudiantes con un sentido crítico de las opiniones emitidas, a la par con el desarrollo de la habilidad para escuchar los argumentos de los compañeros.

d- Trabajo colaborativo: La dimensión social del estudiante se estimula a través del trabajo en equipo, lo cual se constituye en un factor a tomar en cuenta a la hora de implementar estrategias de aprendizaje. En cuanto al trabajo colaborativo (Gómez \& Acosta, 2003) exponen: "Un equipo es una forma de organización particular del trabajo, donde se busca en conjunto que aflore el talento colectivo y la energía de las personas. Esta forma de organización es particularmente útil para alcanzar altos niveles de calidad en la gestión de una institución o empresa. (...) Es así como el trabajo en equipo puede ser una valiosa ayuda, al generar situaciones que facilitan la aplicación de dinámicas que defienden la exploración y el autodesarrollo mediante la propia experiencia." La importancia de llevar a cabo actividades de este tipo radica en que los alumnos pueden asociarse en torno a un propósito de aula.

e-Trabajo por proyectos: dentro del desarrollo de la propuesta y en cada una de las unidades didácticas, se contempló la creación de un proyecto grupal, el cual también fue objeto de la evaluación final. En D: "Se asignaron grupos de trabajo de 5 estudiantes con la finalidad de retratar a través de un documental una situación propia de sus entornos. A partir de los conceptos trabajados en clase y haciendo uso de sus teléfonos celulares, los estudiantes contarán una historia en el formato del documental." Por otra parte en D: "Más adelante, se brindaron los parámetros para la elaboración del guion para el teatro de títeres. Para ello se utilizó un video que mostraba, desde la realización del escenario hasta la puesta en escena de algunas obras de títeres. 


\section{Evaluación de la enseñanza}

La observación directa, registrada a través del uso del diario de campo, permitió darle una óptica más objetiva al ejercicio evaluativo de la implementación de la propuesta. En este sentido se abordó esta categoría desde la acción docente, la fundamentación conceptual, el interés que suscita en los estudiantes y el fortalecimiento de las habilidades comunicativas.

a- Acción docente: En esta etapa del análisis, se busca establecer de qué manera incidió la labor del docente durante el proceso de enseñanzaaprendizaje y cuáles fueron sus actuaciones frente a los distintos contextos que se presentan en la cotidianidad del aula. Otro elemento a resaltar en la acción docente fue la promoción de la lectura y la escritura a partir de la proyección de imágenes, videos y el desarrollo de talleres grupales. No obstante, ocasionalmente se debió hacer llamados de atención para evitar que los alumnos se dispersaran. "Mientras se llevaba a cabo la exposición se debió llamar la atención de dos estudiantes que usaban audífonos y parecían no tener interés en el desarrollo de la clase". El uso de elementos distractores por parte de los estudiantes se hace cada vez más frecuente en el ambiente educativo y es un fenómeno que se debe contrarrestar con la motivación del estudiantado.

b- Fundamentación conceptual: la preparación de los contenidos teóricos y las distintas estrategias metodológicas orientadas por el docente son una parte esencial en el propósito de alcanzar la finalidad de potenciar las habilidades comunicativas de los estudiantes. En ese sentido, se debe tomar en cuenta el conocimiento disciplinar como lo refiere (Sandin, 2005) "...es el cuerpo organizado de conocimientos sobre un conjunto de cosas o acontecimientos, tales como hechos, datos, observaciones, sensaciones y percepciones, que constituyen elementos básicos del conocimiento o definiciones que delimitan las fronteras de su dominio". (p. 35). A partir de ello, se entiende que el docente debe estar facultado en cuanto al conocimiento de los contenidos. Esto se puede constatar desde los estudios realizados en su disciplina, su conocimiento académico y el apoyo de la bibliografía que emplee para una finalidad en el proceso de enseñanza-aprendizaje.

c- Interés que suscita en los estudiantes: Este factor es fundamental para los participantes del proceso de enseñanza-aprendizaje debido que a través de lograr el interés de los alumnos se pueden lograr muchos de los propósitos que se planteen en aras de fortalecer las habilidades 
comunicativas. En busca de ese propósito, muchas de las actividades propuestas en las unidades didácticas apuntaban a despertar el interés de los estudiantes. Otro de los factores que hacen más atractiva la labor de aprender se centra en el reconocimiento de los saberes previos. De acuerdo con (Ausubel, Novak, \& Hanesian, 1983), la esencia del aprendizaje significativo se resume así: "Si tuviese que reducir toda la psicología educativa a un solo principio, enunciaría este: El factor más importante que influye en el aprendizaje es lo que el alumno ya sabe. Averígüese esto y enséñese consecuentemente"(p. 1). En consecuencia con esta premisa, las actividades aquí propuestas también se dieron desde esta óptica. Las instancias dialógicas en las que los estudiantes manifestaron su parecer frente a los temas fue una de las fortalezas que más incentivaron la participación oral desde sus pre-saberes.

d-Fortalecimiento de las habilidades comunicativas: Los lineamientos curriculares de lengua castellana emitidos por el (Ministerio de Educación Nacional, 1998) establecen en cuanto a las habilidades comunicativas que: "La pedagogía del lenguaje se orientó, desde estos planteamientos, hacia un enfoque de los usos sociales del lenguaje y los discursos en situaciones reales de comunicación. El desarrollo de las cuatro habilidades: hablar, escribir, leer y escuchar se convirtió en el centro de los desarrollos curriculares." Atendiendo este propósito, se mencionan algunos de los avances en el propósito fundamental de este trabajo de investigación. Si bien, la prueba diagnóstico inicial y final dieron cuenta de una notoria mejoría, durante el proceso también se evidenciaron progresiones en las habilidades comunicativas a través del desarrollo de las actividades de aula.

\section{Evaluación del aprendizaje.}

En este apartado se resalta la incidencia de las actividades planteadas en la ejecución de la propuesta. Para ello se tiene en cuenta la actitud y participación, cumplió con los objetivos de aprendizaje y desarrollo de las habilidades comunicativas.

a- Actitud y participación: estos componentes del aprendizaje resulta bastante complejos puesto que dependen de múltiples factores que van desde lo físico hasta lo concerniente con el estado anímico del estudiante. No obstante, las condiciones en que se dan las actividades puede incidir de muchas formas en la disposición con que los alumnos asistan a las sesiones de aula. En principio, reconocer la perspectiva del estudiante es un elemento que ayuda al fortalecimiento de la relación 
maestro-alumno como lo menciona (Vaello Orts, 2005) "En el caso del profesor, precisa conocer a sus alumnos para poder interactuar con ellos e influirles positivamente, para lo cual ha de explorarles y saber qué sienten y piensan, adoptando una actitud escrutadora, de observación activa, poniéndose en la perspectiva del alumno para poder apreciar la «otra cara de la moneda»"(p. 74). Para lograr una actitud receptiva por parte de los estudiantes, la construcción dela unidad didáctica debería ajustarse proporcionalmente teniendo en cuenta sus afinidades y destrezas, además de ajustes en la presentación del tema para hacerlo agradable y accesible para sus alumnos.

b- Cumplió con los objetivos de aprendizaje: para este apartado, se acude directamente al desenlace de cada una de las unidades didácticas implementadas en las que los estudiantes presentaron un proyecto de aula grupal que, a su vez, fue objeto de evaluación a partir de rúbricas que valoraron tanto aspectos conceptuales como de manejo de las habilidades comunicativas. Finalmente, con la revisión de los proyectos finales de cada unidad didáctica, se pudo establecer que sí se cumplió con los objetivos de aprendizaje y que los estudiantes, a la par con la elaboración de los proyectos, recurrieron a estrategias comunicativas para apreciar el trabajo de sus compañeros y dar a conocer el propio.

c- Desarrollo de las habilidades comunicativas: Como se ha venido mencionando a lo largo de este trabajo de investigación, la premisa que contempla el desarrollo de las habilidades comunicativas, surge del planteamiento consignado en los lineamientos curriculares de lengua castellana emitidos porel MEN, en loscualesseresalta que elfortalecimiento de estas habilidades son el centro del desarrollo curricular. Adicionalmente, el desarrollo de estas habilidades se sustenta en la interacción con los otros como lo refiere (Hymes, 1996) citado en (MEN, 1998): "El niño adquiere la competencia relacionada con el hecho de cuándo sí y cuándo no hablar, y también sobre qué hacerlo, con quién, dónde y en qué forma. En resumen, un niño llega a ser capaz de llevar a cabo un repertorio de actos de habla, de tomar parte en eventos comunicativos y de evaluar la participación de otros. Aún más, esta competencia es integral con actitudes, valores y motivaciones relacionadas con la lengua, con sus características y usos, e integral con la competencia y actitudes hacia la interrelación de la lengua con otros códigos de conducta comunicativa..." (p. 25). Es decir, que el escenario propicio para el desarrollo de la competencia comunicativa se gesta en la interacción y en las necesidades comunicativas que inducen a llevar a cabo un acto de habla acorde a las circunstancias. 


\section{Conclusiones}

Después de llevar a cabo el trabajo de investigación que culmina con la propuesta pedagógica, se puede establecer las siguientes consideraciones:

- La planificación de los procedimientos en el aula brinda una perspectiva mucho más amplia del quehacer docente. Esta acción contribuye al análisis reflexivo en pro de optimizar los procesos de acuerdo a las necesidades de aprendizaje.

- Brindar especial atención al desempeño de las habilidades comunicativas en los estudiantes es una forma más amplia de entender el desarrollo del lenguaje ya que abarca más allá de la comprensión lectora que se evalúa en las pruebas estandarizadas.

- Sentar las bases de la investigación a partir de una prueba diagnóstico constituyó un punto de referencia que permitió realizar un acercamiento más detallado del desempeño de los estudiantes en relación al dominio de cada una de las habilidades comunicativas.

\section{Recomendaciones}

- Es importante destacar el valor de llevar a cabo la planificación de las actividades de aula. Este ejercicio ofrece una perspectiva amplia de la aplicabilidad de diversas estrategias para lograr determinado fin de aprendizaje.

- Trabajar en pro del desarrollo de las habilidades comunicativas mejora en gran medida las posibilidades de los estudiantes en los distintos aspectos de los procesos de enseñanza. Se recomienda atender este propósito desde todas las disciplinas académicas.

- Es importante señalar la amplitud del lenguaje en los procesos formativos. Si bien, las pruebas estandarizadas se inclinan más por valorar el desempeño en los procesos de lectura, no se debe desatender la escritura, la escucha y el habla, ya que son fundamentales en la formación de la expresividad en las personas. 
- Se deben concebir los procesos de aprendizaje a partir de la implementación de estrategias que vinculen las afinidades de los alumnos. De esta manera se logra despertar el interés por las temáticas y así hacer que el aprendizaje sea significativo.

- El trabajo colaborativo convoca a la potenciación de las capacidades organizativas en los estudiantes y es una herramienta a tener en cuenta al momento de planificar las actividades de aula.

\section{Referencias bibliográficas}

Acevedo Zapata, S. (2014). Inclusión digital y educación inclusiva. Aportes para el diseño de proyectos pedagógicos con el uso de tecnologías de la comunicación. Revista De Investigaciones UNAD, 13(1), 41-57. doi:http://dx.doi.org/10.22490/25391887.1130

Acevedo Zapata, S. (2015). La formación de profesionales desde la reflexión en la acción con elementos fundamentales de la pedagogía crítica. Revista De Investigaciones UNAD, 14(1), 151 - 169. doi:http://dx.doi.org/10.22490/25391887.1350

Alamo Bernal, M. C., Meza De la Hoz, L. E., Fernández Santos, F., \& Abúndez Najera, E. (2015). Facebook como herramienta educativa en el proceso de enseñanza-aprendizaje en el nivel medio superior. Zona Próxima, 116-127.

Ally, M. (2002). Theory and practice of online learning. Obtenido de Athabasca University: http://cde.athabascau.ca/online_book/ch1.html

Amaya Balaguera, Y. (2015). Guía metodológica ágil, para el desarrollo de aplicaciones móviles "AEGIS-MD". Revista De Investigaciones UNAD, 14(1), 97 - 113.

Aponte, M. (2014). Docentes y literatura: La experiencia de lectura como punto de reflexión. Obtenido de http://www.bdigital.unal.edu.co/41980/1/04868004.2014.pdf

Arrieta, N., Gomajoa, P., \& Soto, L. (2015). Estrategias metodológicas implementadas para la comprensión lectora en tres instituciones. Obtenido de http://repositorio.ucm. edu.co:8080/jspui/bitstream/handle/10839/1114/Nuris\%20de\%20Jesus\%20Arrieta. pdf?sequence $=1$

Ausubel, D. (2002). Adquisición y retención del conocimiento. Una perspectiva cognitiva. Barcelona: Paidós.

Ausubel, Novak, \& Hanesian. (1983). Psicología Educativa: Un punto de vista cognoscitivo. México: Ed. Trillas. 
Bravo, J. (2000). Google Books. Obtenido de www.books.google.com.co/books

Buzan, T. (2002). Cómo crear mapas mentales. Barcelona: Urano.

Chomsky, N. (1999). Aspectos de la teoría de la teoría de la sintaxis. Barcelona: Gedisa.

Contreras, G. C. (2016). Desarrollo de la comprensión en lectura inferencial del grado noveno de un Colegio Público de Bogotá. Obtenido de http://www.bdigital.unal.edu. co/51379/1/52793863.2016.pdf

Corpas, J. (2000). cvc.cervantes.es. Obtenido de http://cvc.cervantes.es/ensenanza/ biblioteca_ele/asele/pdf/11/11_0785.pdf

Correa Parra, S. J. (2012). La lectura comprensiva y la composición de textos como estrategia para el desarrollo de la competencia comunicativa. Obtenido de http://tangara.uis.edu.co/biblioweb/pags/cat/popup/pa_detalle_matbib. jsp?parametros $=160280|\% 20| 4 \mid 13$

Cuesta, C. (2011). Lengua y Literatura: disciplina escolar. Hacia una metodología circunstanciada de su enseñanza. Obtenido de http://www.memoria.fahce.unlp.edu. ar/tesis/te.641/te.641.pdf

Danielson, C., \& McGreal, T. (2000). Teacher evaluation to enhance professional practice. Princeton: Educational Testing Service.

Derechos básicos de aprendizaje. (2015). Derechos básicos de aprendizaje. Obtenido de http://www.colombiaaprende.edu.co/html/micrositios/1752/w3-article-349446.html

Díaz , J. (2001). Mutismo selectivo: fobiafrente a negativismo. Revista de Psiquiatría y Psicología del Niño y del Adolescente, IIV.

Díaz, R. (2014). Plan de estrategias didácticas para la optimizacion de competencias de comprension lectora en los estudiantes de la media general. Obtenido de http:// bdigital.ula.ve/pdf/pdfrevista/resustenta/n4/art12.pdf

Escamilla, A. (1993). Unidades didácticas: una propuesta de trabajo en el aula. Zaragoza: Luis Vives.

Gardner, H. (1983). Estructuras de la mente. La teoría de las inteligencias múltiples. México: Fondo de Cultura Económica.

Gómez, A., \& Acosta, H. (2003). ACIMED. Obtenido de http://scielo.sld.cu/scielo. php?script=sci_arttext\&pid=S1024-94352003000600011\&lng=es\&tlng=es.

Gutiérrez Fresnada, R. (2016). La lectura dialógica como medio para la mejora de la comprensión lectora. Obtenido de file:///E:/Descargas/15017-58234-2-PB\%20(1).pdf

Gutiérrez, D. (2017). El taller como estrategia didáctica. Razón y Palabra, 3. 
Hernández, F., Maldonado, J., \& Ospina, C. (2015). El pensamiento crítico como disposición: una. Revista interaméricana de investigación, educación y pedagogía, 4.

Hymes, D. (1996). Acerca de la competencia comunicativa. Bogotá: Universidad Nacional de Colombia.

Jiménez Mendoza, W., Luciano Alipio, R., \& Soto Carrión, C. (2014). Influencia de las fuentes de financiamiento externo en el crecimiento y desarrollo de las empresas agroindustriales del distrito de Abancay Apurímac Perú (periodo 2012- 2013). Revista De Investigaciones UNAD, 13(1), 261-273. doi:http://dx.doi. org/10.22490/25391887.1141

Kemmis, \& Mctaggart. (1988). Cómo planificar la investigación acción. Barcelona: Laertes.

Kress, G., \& Van Leeuwen, T. (1996). Reading Images: The Grammar of Visual Desing. Londres: Routledge.

Llorente, E. (2000). Imágenes en la enseñanza. Revista de Psicodidáctica, 7.

Lobo, J. (2016). Actividades lúdico-recreativas como estrategia para mejorar la comprensión lectora en los estudiantes del grado décimo uno de la institución educativa Agustina Ferro de la ciudad de Ocaña. Obtenido de http://koha.unab.edu.co/ cgi-bin/koha/opac-detail.pl?biblionumber=165696\&query_desc=an\%3A168

López Navarro, M. (s.f.). Edudactica. Obtenido de Modelo para la programación de una unidad didáctica: http://www.edudactica.es/Docus/Recursos/Modelo\%20 Programar\%20UD.pdf

Lurán Rivero, A., Buenahora Tobar, M., \& Vargas Granados, C. (2015). Perspectiva del aprendizaje tradicional y del aprendizaje con comunicación bidireccional en actividades educativas. Revista De Investigaciones UNAD, 14(1), 253-262. doi:http://dx.doi. org/10.22490/25391887.1468

Mariño, S., \& Cendales, G. (2004). Educación No Formal y Educación Popular: hacia una pedagogía del diálogo cultural. Caracas: Federación Internacional de Fe y Alegría.

MEN. (1998). Lineamientos curriculares de lengua castellana. Bogotá: Cooperativa editorial magisterio.

MEN. (2006). Estandares básicos de competencias del lenguaje. Obtenido de http:// www.mineducacion.gov.co/1621/articles-340021_recurso_1.pdf

MEN. (2016). Colombia Aprende. Obtenido de ISCE (Índice sintético de la calidad educativa): http://aprende.colombiaaprende.edu.co/es/siemprediae/86402

Mineduc. (2013). A viva voz. Lectura en voz alta. Santiago de Chile: Bibliotecas escolare CRA. 
Ministerio de Educación Nacional. (1998). Lineamientos curriculares para lengua castellana. Bogotá: MEN.

Paternina, K. (2016). Propuesta didáctica parala lectura de un texto literario con estudiantes de noveno grado de una institución pública de Bucaramanga. Obtenido de http://tangara.uis.edu.co/biblioweb/pags/cat/popup/pa_detalle_matbib. jsp?parametros $=178255|\% 20| 3 \mid 29$

Recalde España, E., Serna Agudelo, B. N., \& Stella Polo, S. L. (2015). Importancia del uso de las TIC en los procesos. Revista interaméricana de investigación, educación y pedagogía, 5.

Régio, L., Egry, E., \& Apostólico, M. (2015). Consideraciones acerca de la importancia del estudio de saberes necesarios para el afrontamiento de la violencia infantil en la atención primaria de salud. Revista De Investigaciones UNAD, 14(2), 137-149. doi:http://dx.doi.org/10.22490/25391887.1463

Sánchez, H. (2009). Una imagen enseña más que mil palabras. Revista del instituto de estudios superiores en educación, 3.

Sandin, M. (2005). Retos actuales de la formación en investigación cualitativa en educación. Barquisimeto: UPEL Universidad Pedagógica Experimental LibertadorInstituto de pedagogía.

Sbert, R. (1996). Sobre el aprender a hacer preguntas. Textos de Didáctica de la lengua y de la literatura.

Vaello Orts, J. (2005). Las habilidades sociales en el aula. Madrid: Santillana. 